\title{
OPEN A sciaenid swim bladder with long skinny fingers produces sound with an unusual frequency spectrum
}

\begin{abstract}
Hin-Kiu Mok ${ }^{1,4}$, Shih-Chia Wu ${ }^{1}$, Soranuth Sirisuary ${ }^{2} \&$ Michael L. Fine ${ }^{3 凶}$
Swim bladders in sciaenid fishes function in hearing in some and sound production in almost all species. Sciaenid swim bladders vary from simple carrot-shaped to two-chambered to possessing various diverticula. Diverticula that terminate close to the ears improve hearing. Other unusual diverticula heading in a caudal direction have not been studied. The fresh-water Asian species Boesemania microlepis has an unusual swim bladder with a slightly restricted anterior region and 6 long-slender caudally-directed diverticula bilaterally. We hypothesized that these diverticula modify sound spectra. Evening advertisement calls consist of a series of multicycle tonal pulses, but the fundamental frequency and first several harmonics are missing or attenuated, and peak frequencies are high, varying between $<1-2 \mathrm{kHz}$. The fundamental frequency is reflected in the pulse repetition rate and in ripples on the frequency spectrum but not in the number of cycles within a pulse. We suggest that diverticula function as Helmholz absorbers turning the swim bladder into a high-pass filter responsible for the absence of low frequencies typically present in sciaenid calls. Further, we hypothesize that the multicycle pulses are driven by the stretched aponeuroses (flat tendons that connect the sonic muscles to the swim bladder) in this and other sciaenids.
\end{abstract}

The family Sciaenidae contains 66 genera and almost 300 species $^{1}$. Sciaenids, the subject of important fisheries, are known for their vocalizations leading to the common names croakers or drums. Males in most species emit choruses of croaking or drumming sounds, typically after dusk and sometimes before dawn during the reproductive season ${ }^{2-6}$.

Sciaenids contract sonic muscles that drive swim bladder vibration and sound production ${ }^{7-9}$. Family members have two types of sonic muscles based on their origin and insertion. Extrinsic muscles, the typical condition, originate on a ventral tendon or possibly on lateral muscles, line the edge of the body cavity inside hypaxial trunk muscles and insert on an aponeurosis attached to the dorsal surface of the bladder ${ }^{4,9-13}$. Intrinsic sonic muscles adhere completely to the swim bladder wall ${ }^{10,13}$ and likely represent a derived condition from an extrinsic precursor $^{14}$.

Most sciaenid species exhibit sexual dimorphism with sonic muscles only in males ${ }^{7,12,13,15}$. However, there are several species including Micropogonias undulatus, Micropogonias furnieri, Argyrosomus japonicus, Larimichthys crocea, and Pogonias cromis ${ }^{12,16-19}$ in which both sexes possess sonic muscles although muscles are larger in male Atlantic croaker ${ }^{12}$. Female sound production in M. furnieri and Pogonias cromis has been evoked by holding or chasing them ${ }^{18,19}$, and male and female Japanese croaker Argyrosomus japonicus and meagre Argyrosomus regius produce sounds during the mating $\operatorname{season}^{3,20}$. Otherwise female sound production has not been studied in the family.

Boesemania microlepis (Boeseman croaker or smallscale croaker), a highly desirable food fish, can grow to over $1 \mathrm{~m}$ and weigh $6 \mathrm{~kg}^{21,22}$. It is the only described freshwater sciaenid in the Indo-west Pacific area ${ }^{1}$ and one of the few freshwater sciaenid species found outside of the Americas ${ }^{23,24}$. It lives in rivers in Cambodia, Laos, Indonesia, Malaysia, in Vietnam's Mekong basin, and Thailand. According to an unpublished report by Borsani quoted by Baird ${ }^{22}$, B. microlepis' sounds last about $100 \mathrm{~ms}$ and include energy to $6 \mathrm{kHz}$ with a peak frequency of

${ }^{1}$ Department of Oceanography, National Sun Yat-Sen University, Lien-hai Rd., Kaohsiung 80424, Taiwan, R.O.C.. ' ${ }^{2}$ Department of Aquaculture, Faculty of Fisheries, Kasetsart University, 50 Ngam Wong Wan Rd., Ladyaow Chatuchak, Bangkok 10900, Thailand. ${ }^{3}$ Department of Biology, Virginia Commonwealth University, Richmond, VA 23284-2012, USA. ${ }^{4}$ National Museum of Marine Biology and Aquarium, 2 Houwan Road, Checheng, Pingtung 944, Taiwan, R.O.C.. ${ }^{\square}$ email: mfine@vcu.edu 


\begin{tabular}{|l|l|l|l|}
\hline Recording site & Concrete Tank & Krasieo Reservoir & Bang Pakong River \\
\hline Calls analyzed & 62 & 62 & 10 \\
\hline Pulses/call (range; mean \pm SD) & $6-32 ; 15.1 \pm 4.71$ & $7-25 ; 15.6 \pm 4.2$ & $8-14 ; 12.0 \pm 1.6$ \\
\hline Call duration (ms; mean \pm SD ) & $53.0-290.0 ; 138.9 \pm 43.8$ & $114.7 \pm 37.9$ & $108.2 \pm 14.5$ \\
\hline Pulse repetition rate (mean \pm SD) & $108.6 \pm 6.6$ & $110.3 \pm 0.4$ & $113.4 \pm 7.3$ \\
\hline Cepstrum spike (ms) & $9.6 \pm 0.2$ & $9.4 \pm 0.3$ & $8.5 \pm 0.1$ \\
\hline Pulse period (ms; mean \pm SD & $9.5 \pm 0.6$ & $9.2 \pm 0.4$ & $8.7 \pm 0.2$ \\
\hline Pulse duration (ms; mean \pm SD) & $7.3 \pm 1.1$ & $5.3 \pm 0.9$ & $6.7 \pm 0.5$ \\
\hline Cycles/pulse (range; mean \pm SD) & $12-16 ; 14.8 \pm 1.1$ & $17-20 ; 19.1 \pm 1.1$ & $9-11 ; 9.7 \pm 1.0$ \\
\hline Cycle duration (ms; range; mean \pm SD) & $0.6-0.7 ; 0.7$ & $0.5-0.7 ; 0.5$ & $0.7-1.3 ; 0.9 \pm 0.2$ \\
\hline $\begin{array}{l}\text { Mean fundamental frequency (Hz) (estimated by the cepstrum } \\
\text { spike) }\end{array}$ & 103.9 & 106.2 & 117.5 \\
\hline Mean dominant frequency (Hz) & 1263 & 2065 & 969 \\
\hline Main frequency peaks (Hz) & $800-1000$ & $1000-1800$ & 825 \\
\hline & $1600-1700$ & $1900-2500$ & 1000 \\
\hline Frequency range (Hz) & $390-3840$ & $760-3800$ & $230-2100$ \\
\hline
\end{tabular}

Table 1. Acoustic characteristics for Boesemania microlepis advertisement calls from a concrete tank, the Krasieo Reservoir, and the Bang Pakong River, Thailand.

$0.5 \mathrm{kHz}$. However other frequency and temporal characteristics of the call and sound-producing muscles have not been described, and no formal data have been reported. Staff members at the B. microlepis Propagation Station in Thailand stated that the fish starts to call in late afternoon and continues after sunset.

Boesemania microlepis has an unusual swim bladder with six long-slender diverticula on each side projecting caudally to the back of the bladder ${ }^{10,25,26}$. The function of these diverticula has not been examined, and we hypothesized that they affect sound spectra. The aims of this study were to describe its swim bladder, sonic muscles and aponeurosis in more detail, its sound characteristics in captivity and in natural waters and determine periods of vocal activity. We find an unusual frequency spectrum that de-emphasizes low frequencies, which we ascribe to the diverticula functioning as Helmholz absorbers.

\section{Results}

Boesemania microlepis advertisement calls were composed of a series of 6-32 pulses (mean \pm SD: $15.1 \pm 4.7$ pulses) with a repetition rate of $95-123 \mathrm{pps}(108.5 \pm 6.6 \mathrm{pps})$ (Table 1, Figs. 1, 3). Pulse duration varied from 3.4 to $9.4 \mathrm{~ms}(7.3 \pm 1.1 \mathrm{~ms})$ and contained $12-16$ cycles $(14.8 \pm 1.1)$ adding up to a call duration from 53 to $290 \mathrm{~ms}(139.0 \pm 43.8 \mathrm{~ms})$ for each burst of pulses. Number of pulses and call duration were positively correlated $\left(\hat{y}=0.0091 X+0.00205 ; r^{2}=0.96\right)$. Amplitude of most calls increased from the first to the 3rd-6th pulse (mode was the 4th), after which amplitude stabilized although the final pulse and sometimes the last few pulses decreased in amplitude (Fig. 1).

Call pulses were tonal with numerous harmonics (Figs. 1, 2, 3). Parameters from the three recording sites were mostly similar but with some differences (Table 1). Unlike typical swim bladder sounds, calls had unusual spectra with decreased amplitudes at low and increased amplitudes at high frequencies. Frequencies of the calls in the tank, reservoir and river ranged from 390-3840, 760-3800, and 230 to $2100 \mathrm{~Hz}$, respectively (Figs. 2, 3). Two main frequency bands occurred in the tank (900-1000 and 1450-1800 Hz) and reservoir calls (1580-1660 and 2000-2500 Hz), and river calls had dominant bands at ca 400-500 and ca. $850 \mathrm{~Hz}$. Cepstrum analysis gave a spike at ca. $9.5 \mathrm{~ms}$ for the tank and reservoir calls and $8.5 \mathrm{~ms}$ for the river calls, equivalent to an $\mathrm{F}_{0}$ of $105 \mathrm{~Hz}$ and $118 \mathrm{~Hz}$, respectively (Table 1), which matches the pulse repetition rates of these calls. Numerous small harmonic oscillations occurred at multiples of the fundamental frequency of ca. $105 \mathrm{~Hz}$ presented in the power spectra (Figs. 2, 3).

Nocturnal pattern of sound production. From 11 to 13 March 2011 vocal activity in the tank began at ca. 1815 hours, peaked between 2000 and 2015 and terminated at ca. 2105 (Fig. 4a). Owing to the small number of fish, calls did not form a continuous chorus, and individual pulses were clear. In the peak period, there were 1072-1447 calls per 5-min. In all three evenings vocal activity started with a few short calls and increased to longer calls (e.g. 23-28 pulses/call) peaking at the end of the first hour (Fig. 4b) before gradually decreasing toward the end of the vocal period.

Sexual dimorphism of the sonic muscles. The swim bladder is carrot-shaped with a slightly restricted zone at its anterior neck region (Fig. 4). It has a pair of branched cephalic appendages that extend toward the head through the septum transversum ${ }^{13}$. Six additional pairs of fingers (diverticula) originate from the anterior sides and extend caudally ending at the termination of the bladder lumen but before the posterior tip of the swim bladder (Fig. 5a). The anterolateral most finger was shortest. The openings to the diverticula form a relatively straight rostrocaudal line that extends approximately $1.5 \mathrm{~cm}$. Males have a typical red-colored extrinsic sonic muscle surrounding the swim bladder behind the narrow neck (Fig. 5b,c). The sonic muscle attaches to its 


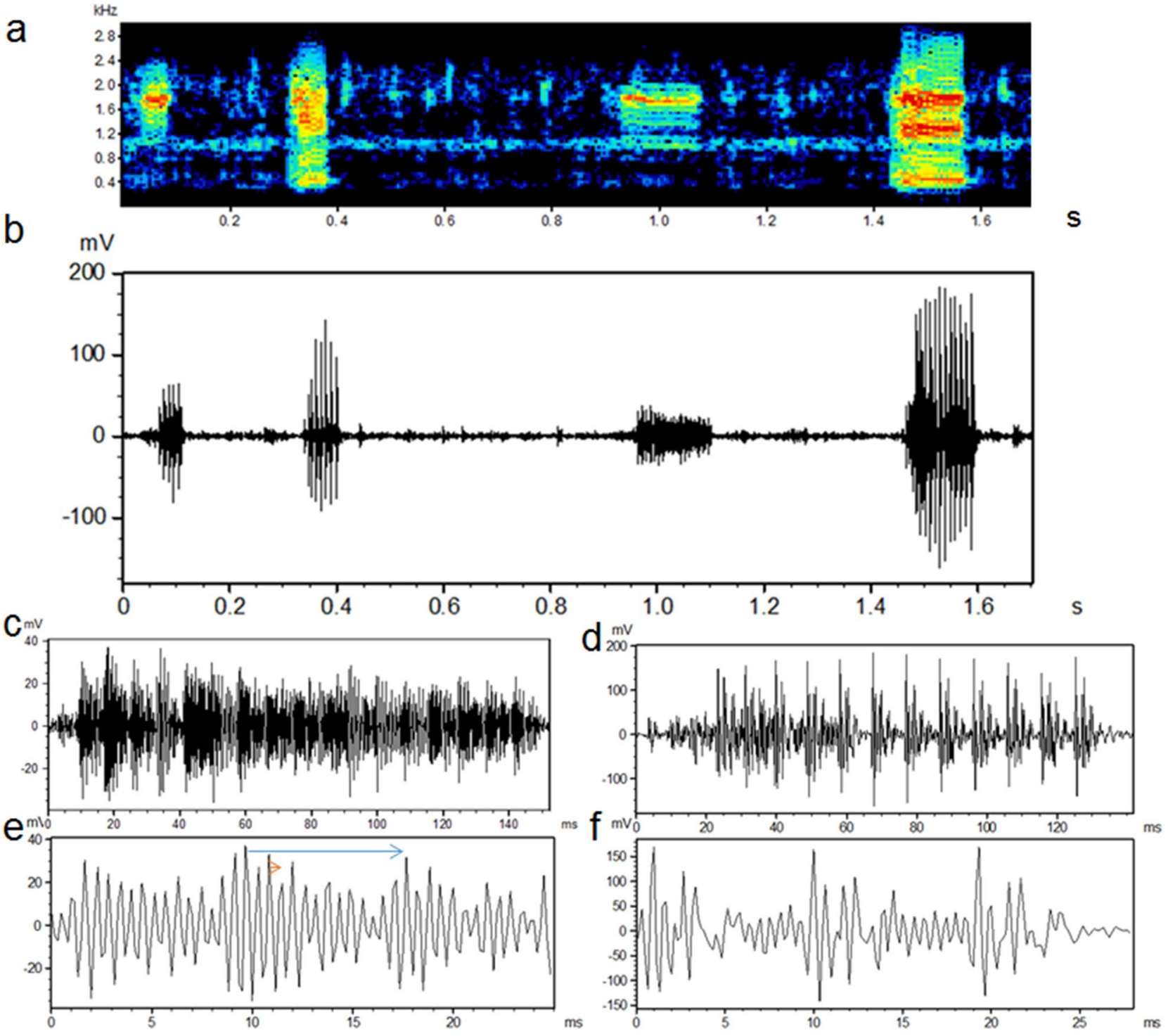

Figure 1. Spectrogram (a) and oscillograms (b) for 4 captive Boesemania microlepis calls recorded in a cement tank. The waveform is expanded for the third $(\mathbf{c}, \mathbf{e})$ and fourth call $(\mathbf{d}, \mathbf{f})$. The pulse-period (blue arrow) and cycle period (short orange arrow) is shown in $(\mathbf{c}) . \mathrm{FFT}=128$; overlap $=75 \%$; Hamming window.

insertion, a typical aponeurosis above the bladder. However, there is an unusual thickened collar at the anterior edge of the dorsal aponeurosis (Fig. 5d). The muscles curve around the body wall adjacent to hypaxial trunk muscle. The internal side of the trunk muscle is sheathed by the parietal peritoneum separating it from the sonic muscle. The peritoneum extends ventrolaterally on the internal surface of the sonic muscle, becoming a thin ventral aponeurosis that extends across the ventral mid-line of the abdomen. Sonic muscle fascicles originate on the internal surface of the lower parietal peritoneum (ventral aponeurosis) between the sonic muscle and the hypaxial trunk muscle. The origin can be mistakenly assumed to attach to hypaxial muscles ventrolaterally in incompletely-dissected specimens. The ventral aponeurosis thickens in an Asian sciaenid (i.e., Otolithes ruber; Mok, personal observation). Females lack sonic muscles and both aponeuroses.

\section{Discussion}

Similar to many sciaenids, $B$. microlepis produces calls in late afternoon into evening ${ }^{2-4,6,15,27-30}$. Calls are composed of a rapid series of pulses with a repetition rate of slightly $>100 \mathrm{pps}$. Pulses are relatively long (ca $7 \mathrm{~ms}$ ), tonal and composed of multiple cycles (ca 10-20), each $<1 \mathrm{~ms}$ in duration. The pulse repetition rate matches a cepstral spike $<10 \mathrm{~ms}$ that is not present in background noise. In weakfish Cynoscion regalis emg recordings indicate one muscle contraction per sound pulse $\mathrm{e}^{8}$. Rapid oscillations of $<1 \mathrm{~ms}$ are too fast to be caused by individual muscle contractions, and we therefore suggest that each pulse, but not cycles within a pulse, is driven by an individual contraction of the paired sonic muscles.

Except for peak or dominant frequency, sound parameters were relatively consistent across the three sites. In our experience with fish sounds having multiple peaks, two sounds, even from the same fish, may have adjacent 
a do

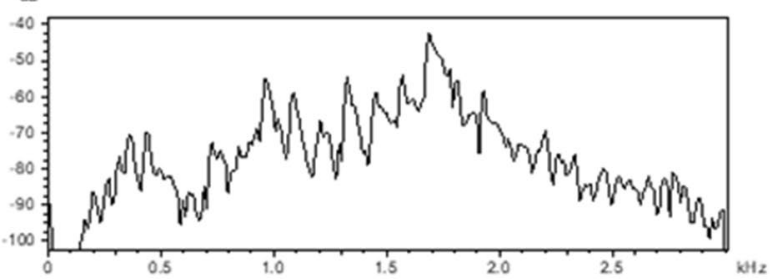

$\mathrm{C}_{\text {a }}$

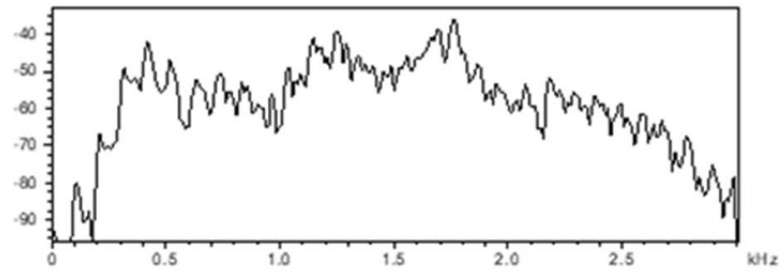

e

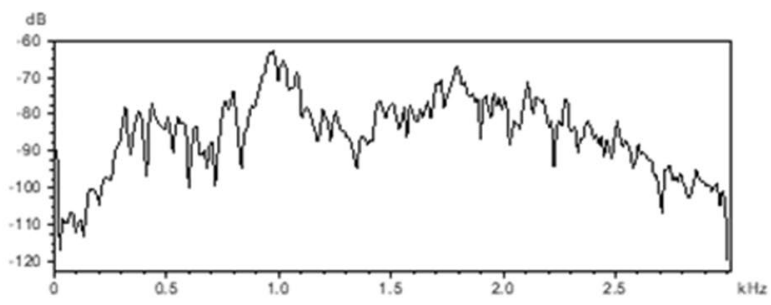

$\mathrm{b}$

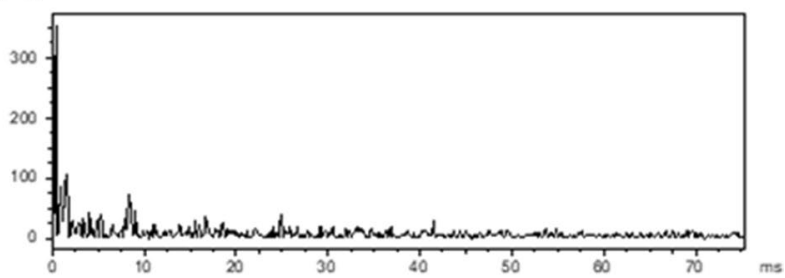

d

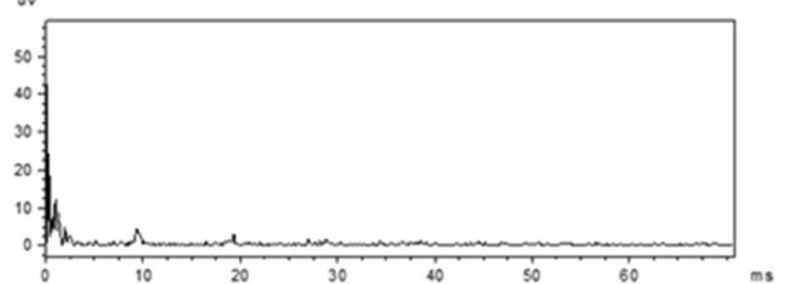

f

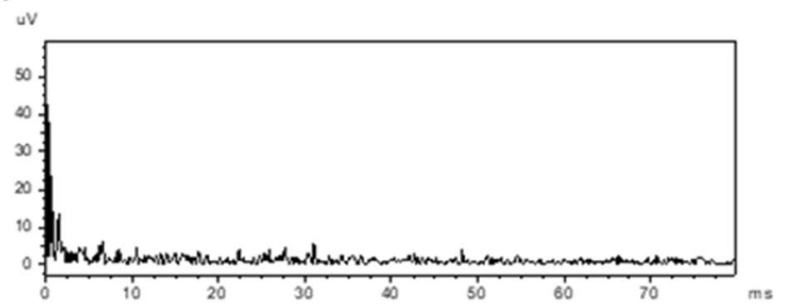

Figure 2. Power spectra (left graphs) and cepstra (right graphs) for the third (a,b) and fourth call (c,d) and background noise (e,f) in Fig. 1.

$\mathrm{kHz}$

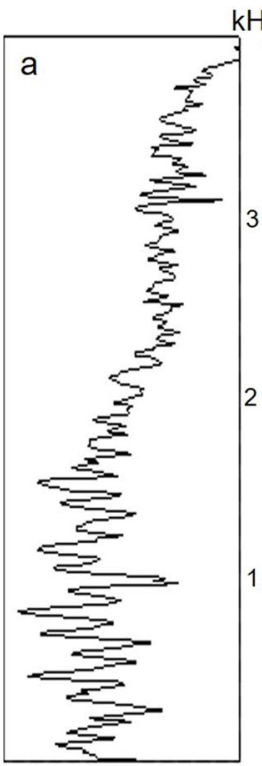

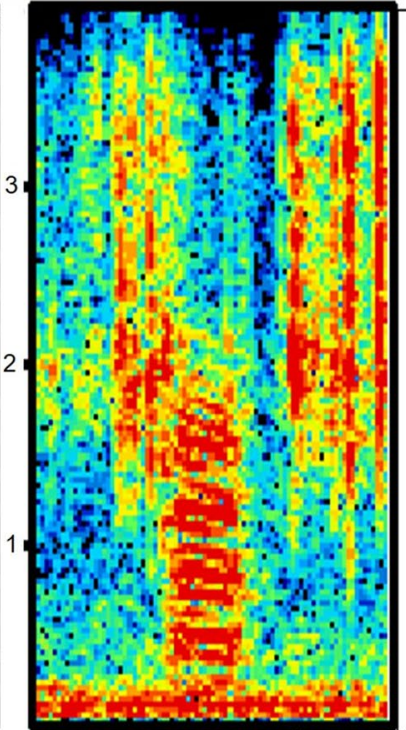

$0.5 \mathrm{~s}$

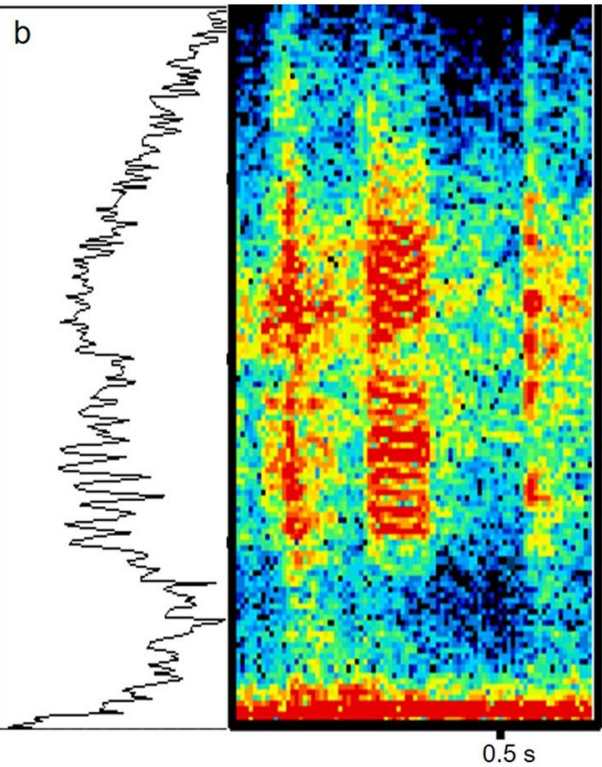

Figure 3. Spectrogram and power spectrum of wild Boesemania microlepis tonal calls recorded in the Bang Parkong River (a) and Krasieo Reservoir (b). Power spectrum FFT =256; overlap =75\%; Hamming window. The power spectra encompass the tonal sounds and the low-frequency background noise below $0.25 \mathrm{kHz}$. 

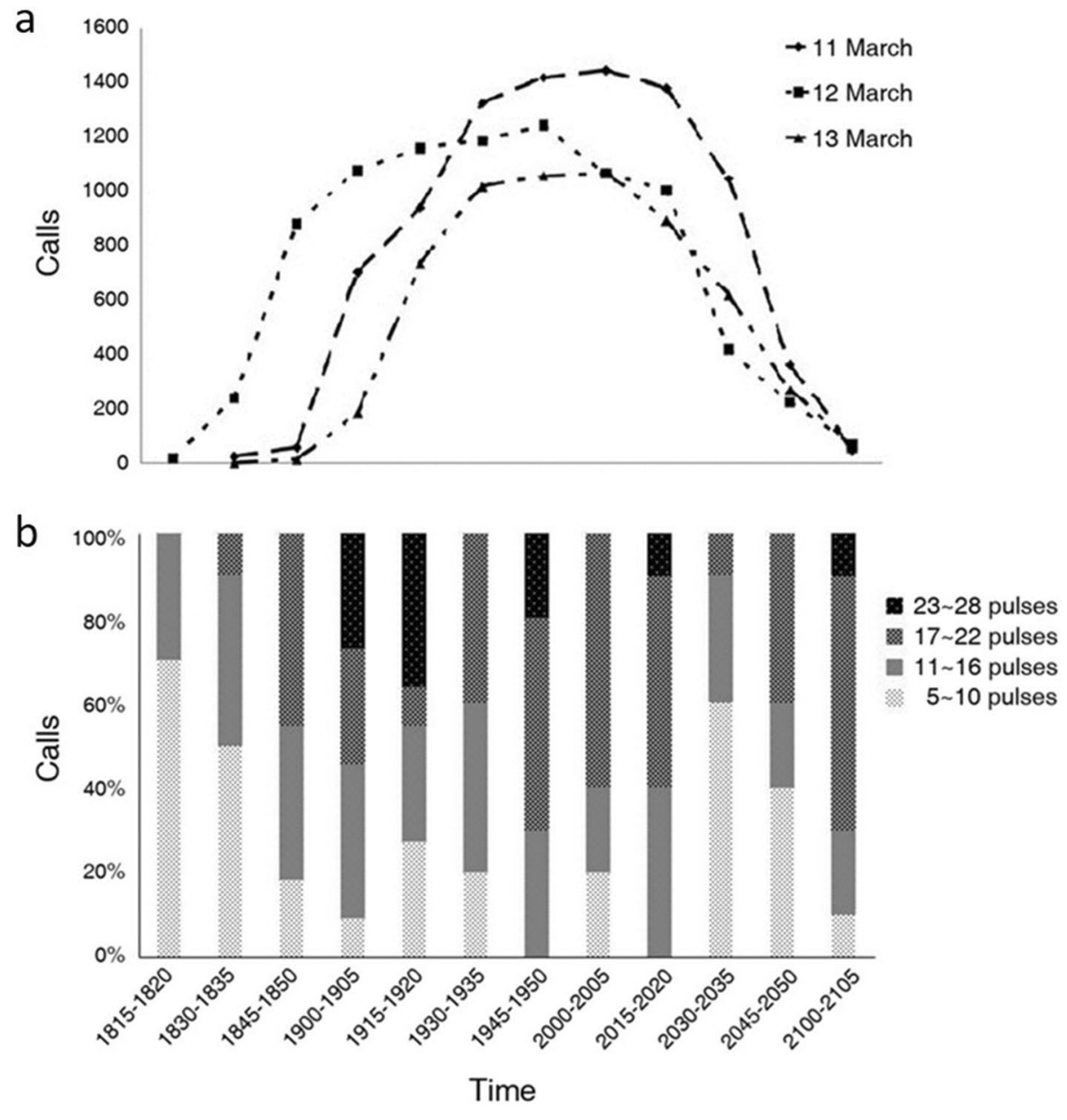

Figure 4. Temporal changes in Boesemania microlepis calls. (a) number of calls in three consecutive evenings from 11 to 13 March 2011 and (b) occurrence of calls with varying pulse numbers in the evening of March 12, 2011.

peaks that alternate in terms of the greatest amplitude (Mok and Fine personal observations). Therefore, this metric may not be as definitive, simple or meaningful as it sounds, particularly when different peaks are averaged. The frequency spectrum of $B$. microlepis calls is highly unusual in several respects. Spectra have several peaks at frequencies between $<1$ to $2 \mathrm{kHz}$ and an absence of low frequencies that would be expected at multiples of the

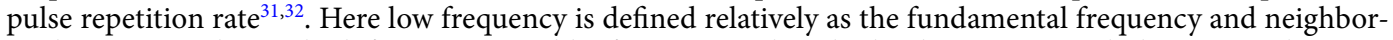
ing harmonics whereas high frequency would refer imprecisely to higher harmonics, including energy between 1-2 kHz. The fundamental frequency and the next three harmonics are absent or attenuated. However, within the broad-frequency band between $1-2 \mathrm{kHz}$, there are smaller oscillations at ca $100 \mathrm{~Hz}$ intervals, apparently harmonics of the missing fundamental frequency. In the oyster toadfish for instance, one of the best understood examples of swim bladder sound generation ${ }^{31,32}$, most energy occurs at the fundamental frequency and the second and third harmonics ${ }^{29,33,34}$, which surprisingly are missing in B. microlepis. There are several potential reasons for this unusual spectrum including environmental filtering by shallow water and tank artifacts, potential resonant frequency of the swim bladder, or the unusual swim bladder morphology that could turn the swim bladder into a high-pass filter. These topics will be considered briefly.

Environmental filtering. As is common, none of the fish in this study were recorded under ideal conditions. Fish in the cement tank were within a maximal distance of $1.5 \mathrm{~m}$ from the hydrophone whereas fish in the river and reservoir were at unknown distances and depths in deeper water. However, the hydrophone was close to shore in shallow water that would diminish low frequencies with long wavelengths ${ }^{35-38}$. Still sounds from the three disparate sites all had attenuated low frequencies and a broad frequency representation at higher frequencies (peak frequencies of $1263 \mathrm{~Hz}, 2065 \mathrm{~Hz}$, and $969 \mathrm{~Hz}$ for the tank, reservoir and river respectively). Although calculations for the tank indicate a resonant frequency of $1029 \mathrm{~Hz}^{39}$, it is clear that sounds did not exhibit a strong peak at this frequency. Furthermore, recordings of characiform (Prochilodus argenteus, $P$. costatus, $P$. lineatus) and sciaenid (Argyrosomus regius, Sciaenops ocellatus and Umbrina cirrosa) fishes in cement tanks with relatively similar dimensions exhibited low frequency energy $y^{6,40}$. We therefore conclude that the call spectrum of B. microlepis is largely related to energy produced by the fish although it is affected by the environment. 


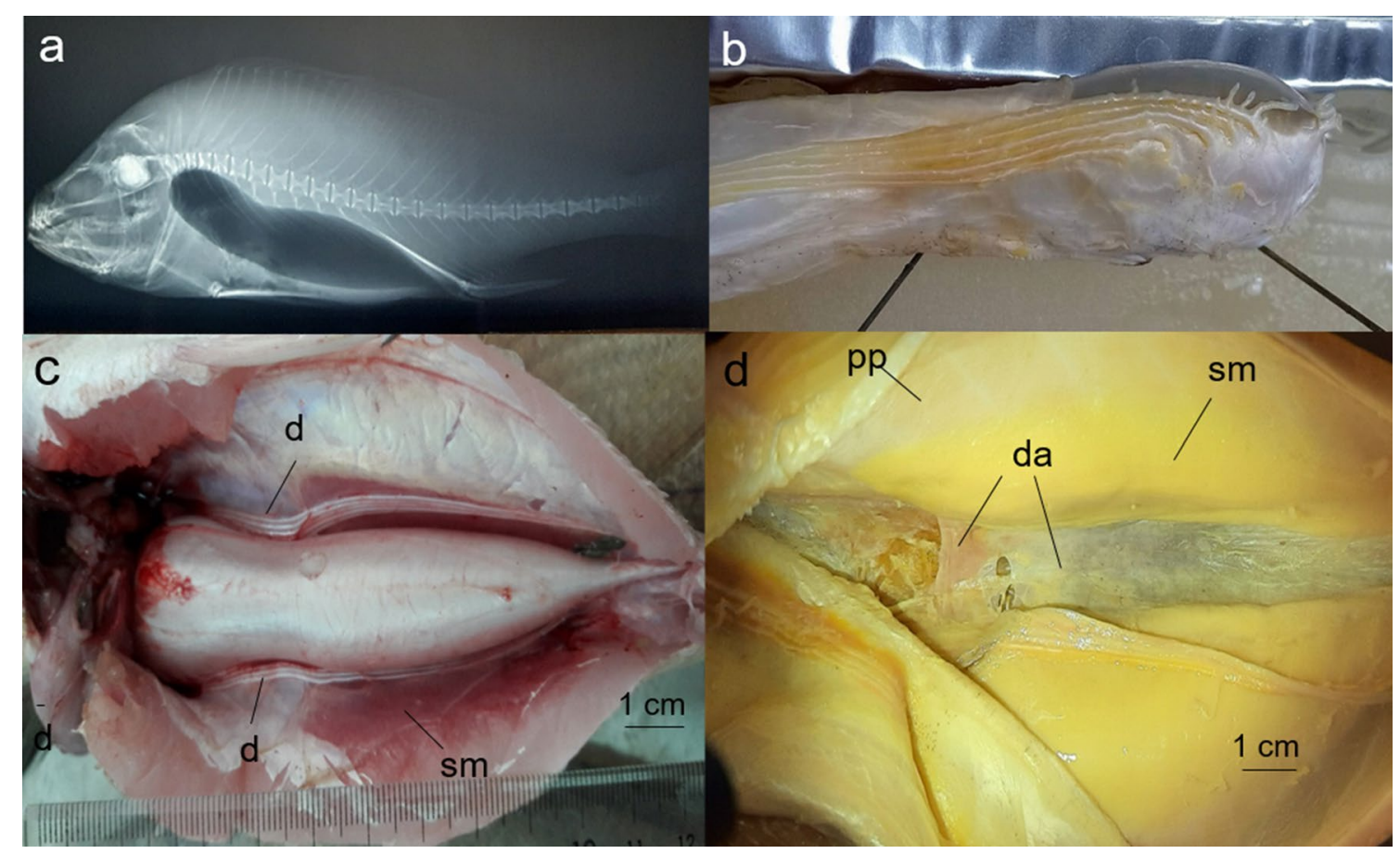

Figure 5. Boesemania microlepis swim bladder, diverticula sonic muscles and aponeurosis. (a) Radiograph showing the swim bladder. (b) Photograph of the swim bladder removed from the fish showing close up of diverticula. (c) Photograph of the swim bladder diverticula and sonic muscles. (d) Photograph of a fixed specimen with the swim bladder removed showing the dorsal aponeurosis and sonic muscle. The fish had a standard length of $=260 \mathrm{~mm}$ and a swim bladder length of $116 \mathrm{~mm}$. The black lines in (b) are pins to hold the swim bladder in place. $d$ diverticula, $d a$ dorsal aponeurosis, $p p$ parietal peritoneum, sm sonic muscle.

Resonant frequency of the swim bladder. Historically fish swim bladders were modeled as underwater resonant bubbles whose frequency decreases with size and increases with hydrostatic pressure, e.g. depth ${ }^{42}$. The equation of bubble resonant frequency ${ }^{41,42}$ indicates a resonant frequency of $740 \mathrm{~Hz}$ at $0.8 \mathrm{~m}$ depth for a $34 \mathrm{~cm}$ SL B. microlepis with a swim bladder length of $10 \mathrm{~cm}$ and radius of $2 \mathrm{~cm}$ (corrected for an elongated shape following Weston ${ }^{42}$ ). The equation does not predict the frequency peaks found in the calls. Bubbles are sharply tuned unlike the broad relatively flat spectrum of the fish's call, which contains multiple peaks. Although it was recognized that fish sounds and sonar returns from fish with swim bladders were less sharply tuned than from a bubble, early interpretations posited damping by surrounding fish tissue $\mathrm{e}^{43,44}$. Work in the oyster toadfish suggested a new paradigm, namely that sounds are produced as a forced rather than a resonant response ${ }^{32}$, e.g. the muscle contraction rate sets the fundamental frequency, which explains why a field chorus of boatwhistles produced by multiple differently-sized individuals can have a narrow range of fundamental frequencies on the order of $10 \mathrm{~Hz}^{45}$. Toadfish sounds decay rapidly following the final muscle contraction indicating that the bladder is responsible for rapid damping ${ }^{32}$. The swim bladder has a high water content (viscous damping) and multiple layers of collagen and elastin, which serve to rapidly attenuate sounds ${ }^{46}$. Therefore, the expression of resonance of the internal bubble is inhibited. Although weakfish sounds decrease in frequency with fish size, the decrease has been related to a longer contraction time of larger muscles and is therefore still a forced response ${ }^{8}$.

Recently a third possibility has been identified in fish sound production in which sonic muscles are connected to a tendon or bone that attaches to the swim bladder, and the stretched and recoiling tendon forces swim bladder movement ${ }^{14,47-49}$. Such sounds will decrease in frequency with fish and tendon or bone size and have multiple cycles following muscle contraction unlike the simple sonic muscle swim bladder system that decays rapidly.

Relationship of swim bladder morphology to sound spectrum. The swim bladder of $B$ microlepis is carrot-shaped terminating in a skinny ducktail, common in sciaenids ${ }^{10,26}$, but the bladder has two unusual modifications. One is a partial constriction toward the back of the anterior end at the rostral edge of the sonic muscles. The constriction may represent an intermediate condition between a simple swim bladder and one that has divided into two chambers as in silver perch and several other sciaenids ${ }^{25,50}$ and many otophysan fishes including some catfishes, characiforms, and cyprinids ${ }^{51-53}$. The anterior neck region bears a number of projections: a rostral pair heads toward the ears ${ }^{26}$ and six (typically) on each side project in a caudal direction ending near the termination of the swim bladder lumen. Caudal to the anterior region, the sonic muscles terminate on a dorsal aponeurosis connecting to the swim bladder, and they originate on a thickened ventral peritoneum separating the sonic muscle and hypaxial muscles. A ventral connection between the sonic muscles has been mentioned for weakfish Cynoscion regalis ${ }^{11}$ and Atlantic croaker Micropogonias undulatus ${ }^{9}$. In Atlantic croaker, material properties (stress at break and Young's modulus) are greater in the aponeurosis than in bladder tissue although 
strain is similar ${ }^{54}$ suggesting that the aponeuroses will be stretched by the sonic muscle, acting like a tendon, and transfer muscle strain energy back to the swim bladder. Based on geometry, the middle to back part of the bladder will be compressed during muscle contraction forcing gas into the anterior region, which will expand. The stretched tendon likely explains the multiple cycles caused by a single muscle contraction ${ }^{55}$.

Diverticula. There has been almost no experimental work on the various diverticula of sciaenids and no insight as to their ancestral function or how they might have evolved. Locascio and Mann ${ }^{56}$ suggested that multiple tubercles on the swim bladder in black drum Pogonias cromis increase the bladder's surface area, which would increase volume velocity and therefore sound amplitude ${ }^{32,57}$. Yan and Fine (unpublished) examined hearing in four Atlantic sciaenids with a range in diverticula length: long terminating adjacent to the ears (sliver perch and weakfish), medium (typically extending to the pericardium in Atlantic croaker) and minimal (spot). Deflation of swim bladder gas via a syringe caused a $>10 \mathrm{~dB}$ decrease in auditory thresholds in silver perch and weakfish but had no effect in croaker or spot. Therefore, the swim bladder only aids hearing when diverticula terminate close to the ears ${ }^{58,59}$. As with silver perch which can hear to $4 \mathrm{kHz}^{50}$, it is likely that $B$. microlepis, with two long anterior diverticula ${ }^{26}$, has sensitive high-frequency hearing, which would match the elevated frequency distribution of its sounds. Such elevation would increase their communication frequency band above much of background noise caused by waves and bubbles and sounds produced by other nonspecialized fishes, e.g., a relatively unobstructed sound channel.

The waveform of black drum advertisement calls, a sciaenid ${ }^{18,56,60}$, shares similarities with the toadfish boatwhistle ${ }^{32}$ : both produce a long tonal call in which each contraction causes a sound cycle, and the sound attenuates rapidly following the final contraction. Both species have intrinsic muscles, and both however are unlike typical sciaenid calls that have a more complex waveform. For instance, the weakfish sound pulse has at least two cycles for each muscle action potential $(\mathrm{emg})^{8,61}$. A number of sciaenids produce multiple cycles per sound pulse-considerably more than two-including Sciaenia umbra ${ }^{62}$, Cynoscion guatucupa ${ }^{63}$, Aplidinotus grunniens ${ }^{64}$, and Umbrina canosa $i^{65}$. Therefore, of the three potential mechanisms of swim bladder sounds (resonant bladder, forced response determined by sonic muscles or forced response determined by muscles with an intermediate tendon or bone), sciaenid sounds are likely caused by the third mechanism, e.g. multiple cycles determined by a combination of the dorsal and ventral aponeurosis continuing to excite the bladder. This statement requires experimental verification, but with current knowledge, it is a parsimonious interpretation.

Absence of low frequencies in the call spectrum. We hypothesize that the multiple side appendages turn the swim bladder into a high-pass filter that will function as a Helmholz absorber ${ }^{66,67}$, a concept unexplored in fish bioacoustics. Tang ${ }^{66}$ notes Helmholtz resonators are widely used as silencing devices in ducted systems because of their strong sound attenuation and have been useful in dealing with the low-frequency noise propagating inside air conditioning ductworks. We suggest that that pressure from the gas being pushed into the long slender diverticula of the swim bladder will be dissipated by friction at low frequencies and favored at higher frequencies. The lateral most diverticulum is notably shorter than the others, which also have different lengths depending on their rostrocaudal position as they exit the bladder. Therefore, the different diverticula may be tuned to somewhat different frequencies. Additionally, we are unaware of how soft pliable material capable of viscous damping ${ }^{46}$ will affect the system. Our hypothesis clearly requires experimental evidence for confirmation.

Species distribution. Boesemania microlepis lives primarily in freshwater ${ }^{22}$ but may also occur in estuaries $^{68}$. Conversely, Aspericorvina jubata, another sciaenid, occurs in shallow coastal waters and occasionally enters estuaries and rivers ${ }^{68}$. Therefore, B. microlepis and $A$. jubata are the only identified sciaenid species that can possibly be found in the rivers connected to the Gulf of Thailand. Whether the former can extended into the upstream section of the Bang Pakong River remains unclear. A possible new sciaenid species called the golden croaker by local fishers has been captured in the lower Bang Pakong River. However, B. microlepis is the only known sciaenid in the tank, reservoir and the upstream part of the Bang Pakong River.

\section{Methods}

Ethical considerations. Observations in this investigation were done in compliance with the ethical rules of the IACUC of National Sun Yat-sen University. The only interaction with living animals was placing a hydrophone in the water; thus no permits were required.

Small scale croakers, B. microlepis, were recorded from captive fish raised at the Freshwater Fisheries Research and Development Centers in Chainat, Thailand, and from wild fish in the Krasieo Reservoir and the Bang Pakong River, Thailand. Recordings in 2011 used an HP-A1 hydrophone (Burns Electronics; frequency range from $10-25,000 \mathrm{~Hz} \pm 3 \mathrm{~dB})$ and a HP-A1 Mixer-amplifier connected to a Korg digital recorder $(\mathrm{MR} \neg 1000,44.1 \mathrm{kHz}$ with 16-bit resolution), and 2019 recordings used a H2A hydrophone (Aquarian Audio Products; useful frequency range: $<10 \mathrm{~Hz}$ to $>100 \mathrm{kHz}$ ) and Sony digital recorder (PCM-M10). For field recordings the hydrophone was attached to a floating platform anchored from shore (suspended $1 \mathrm{~m}$ from the surface at a water depth ca $1.5 \mathrm{~m}$ ). Water temperatures were $29.8^{\circ} \mathrm{C}$ in the Bang Pakong River, $28.2^{\circ} \mathrm{C}$ in the Krasio Reservoir and 28.2 in the Chaopraya River close to the Chainat Fisheries Station.

Twelve captive fish (average total length ca. $40 \mathrm{~cm}$ ) from the fisheries center were recorded in a $3 \times 2 \times 0.8 \mathrm{~m}$ concrete tank filled with freshwater to a $0.7 \mathrm{~m}$ depth between March 11 to 13, 2011 The hydrophone was placed in the center of the concrete tank about $45 \mathrm{~cm}$ beneath the surface. Following the advice of staff members at the Research and Development Center, recording started at 1600 hours and stopped when no calls were produced for $15 \mathrm{~min}$. 
Wild B. microlepis have been confirmed at Krasieo Reservoir located in Dan Chang, Supanburi Province, Thailand (S. Sirisuary personal observation). A possible new Boesemania species lives in the Bang Pakong River in the downstream and estuarine parts of the river), but sound recordings were made at upstream sites in November 2012 where only B. microlepis is known. Krasieo reservoir sounds were recorded from 1600 to 2100 hours, 19, Nov. 2019. Recordings in the Bang Pakong River were made on 3 and 4 November 2012 between 1700 and 1900 hours under a bridge beside the riverbank (near Wat Khao Din, Chon Buri Chaehoengsao).

Sound analysis. Ten tank calls with good signal to noise ratios were chosen from 5 min sections every $10 \mathrm{~min}$ for the three nights. Sounds were analyzed using Raven Pro 1.4 (Bioacoustics Research Program, The Cornell Lab of Ornithology, Ithaca, NY, USA; Charif et al. 2010) and Avisoft-SASLab Pro 5.2.08. We measured call duration (ms), number of pulses per call, pulse repetition rate, inter-pulse interval (IPI, measured from the end of one pulse to the beginning of the next, ms), pulse duration (measured as the time between the beginning to the end of one pulse, $\mathrm{ms}$ ), and major frequency bands. Data are presented as means \pm 1 standard deviation. Frequency parameters were measured from sonograms and temporal features from oscillograms. Cepstral analysis was conducted to reveal call fundamental frequency. In cepstral analysis, an inverse Fast Fourier Transform is applied to a log power spectrum. For a harmonic sound, a sharp spike will be displayed at around $\mathrm{T}$ seconds, the period of the fundamental frequency, calculated by $\mathrm{F}_{0}=1 / \mathrm{T}$. (https://www.phon.ox.ac.uk/jcoleman/ new_SLP/Lecture_7/Cepstral_analysis.html).

Sonic apparatus. Twenty fish (average standard length $40.3 \mathrm{~cm} ; 11$ females and 9 males) were purchased from local fishmongers at Sam Chuk Old Market in Suphan Buri Province, Sam Chuk District on July 9th in 2011 and Nov. 28, 2012. Sex was determined by appearance of the gonads, and gross anatomy of the swim bladder, sonic muscles and aponeuroses was described.

Received: 22 June 2020; Accepted: 7 October 2020

Published online: 29 October 2020

\section{References}

1. Froese, R. \& Pauley, D. (2020) FishBase. World Wide Web electronic publication. https://www.fishbase.org, version (02/2012).

2. Connaughton, M. A. \& Taylor, M. H. Seasonal and daily cycles in sound production associated with spawning in the weakfish, Cynoscion regalis. Environ. Biol. Fish 42, 233-240 (1995).

3. Ueng, J. P., Huang, B. Q. \& Mok, H. K. Sexual differences in spawning sounds of the Japanese croaker Argyrosomus japonicus (Sciaenidae). Zool. Stud. 46, 103-110 (2007).

4. Parmentier, E., Tock, J., Falguière, J. C. \& Beauchaud, M. Sound production in Sciaenops ocellatus: preliminary study for the development of acoustic cues in aquaculture. Aquaculture 432, 204-211 (2014).

5. Parsons, M. J. G., McCauley, R. D. \& Mackie, M. C. Characterisation of mulloway Argyrosomus japonicus advertisement sounds. Acoustics Aust. 41, 196-201 (2013).

6. Bolgan, M. et al. Calling activity and calls' temporal features inform about fish reproductive condition and spawning in three cultured Sciaenidae species. Aquaculture 524, 1-14 (2020).

7. Tower, R. W. The production of sound in the drumfishes, the sea-robin and the toadfish. Ann. N. Y. Acad. Sci. 18, 149-180 (1908).

8. Connaughton, M. A., Taylor, M. H. \& Fine, M. L. Effects of fish size and temperature on weakfish disturbance calls: implications for the mechanism of sound generation. J. Exp. Biol. 203, 1503-1512 (2000).

9. Ladich, F. \& Fine, M. L. Sound-generating mechanisms in fishes: a unique diversity in vertebrates. In Communication in Fishes (eds Ladich, F. et al.) 3-43 (Science Publishers, Enfield, 2006).

10. Chao, L. N. A basis for classifying Western Atlantic Sciaenidae (Teleostei: Perciformes). NOAA Technical Report, Circular 415 (National Oceanic and Atmospheric Administration, Washington, 1978).

11. Ono, R. D. \& Poss, S. G. Structure and innervation of the swimbladder musculature in the weakfish, Cynoscionregalis. Can. J. Zool. 60, 1955-1967 (1982).

12. Hill, G. L., Fine, M. L. \& Musick, J. A. Ontogeny of the sexually dimorphic sonic muscle in three sciaenid species. Copeia 1987, 708-713 (1987).

13. Sasaki, K. Phylogeny of the family Sciaenidae, with notes on its zoogeography (Teleostei, Perciformes). Mem. Fac. Fish. Hokkaido Univ. 36, 1-137 (1989).

14. Mok, H. K. et al. An intermediate in the evolution of superfast sonic muscles. Front. Zool. 8, 1-8 (2011).

15. Lin, Y. C., Mok, H. K. \& Huang, B. Q. Sound characteristics of big-snout croaker, Johnius macrorhynus (Sciaenidae). J. Acoust. Soc. Am er. 121, 586-593 (2007).

16. Griffiths, M. H. \& Hecht, T. Age and growth of South African dusky kob Argyrosomus japonicus (Sciaenidae) based on otoliths. S. Afr. J. Mar. Sci. 16, 119-128 (1995).

17. Lo P. C. Sound characteristics of the large yellow croaker, Larimichthys crocea and phylogeny of the Western Pacific sciaenid genera inferred by molecular evidence. Master's Thesis. National Sun Yat-sen University, Taiwan (2011).

18. Tellechea, J. S., Martinzez, C., Fine, M. L. \& Norbis, W. Sound production in the whitemouth croaker and relationship between fish size and call characteristics. Environ. Biol. Fish. 89, 163-172 (2010).

19. Tellechea, J. S., Norbis, W., Olsson, D. \& Fine, M. L. Calls of the black drum (Pogonius chromis: Sciaenidae): Geographical differences in sound production between Northern and Southern Hemisphere populations. J. Exp. Zool. 313A, 1-8 (2010).

20. Pereira, B. P. et al. Sound production in the Meagre, Argyrosomus regius (Asso, 1801): intraspecific variability associated with size, sex and context. PeerJ 8, e8559 (2020).

21. Wongratana, T. Boesemania microlepis (Bleeker), a common but misidentified riverine drumfish (Pisces: Sciaenidae) from Thailand and Mekong River. In Proceedings of the 23rd Kasetsart University Conference Fisheries Section, Kasetsart University, Bangkok (Thailand), Vol. 23, 3-20 (1985).

22. Baird, I. G., Phylavanh, B., Vongsenesouk, B. \& Xaiyamanivoni, K. The ecology and conservation of the smallscale croaker Boesemania microlepis (Bleeker 1858-59) in the mainstream Mekong River, southern Laos. Nat. Hist. Bull. Siam Soc. 49, 161-176 (2001).

23. Feldberg, E., Porto, J. I. R., Santos, E. B. P. \& Vlantim, F. C. S. Cytogenetic studies of two freshwater sciaenids of the genus Plagioscion (Perciformes, Sciaenidae) from the central Amazon. Gen. Mol. Biol. 22, 351-356 (2020).

24. Boeger, W. A. \& Kritsky, D. Parasites, fossils and geologic history: Historical biogeography of the South America freshwater croakers, Plagioscion spp. (Teleostei, Sciaenidae). Zool. Scr. 32, 3-11 (2002). 
25. Chao, N. L. A synopsis on zoogeography of Sciaenidae. In Indo Pacific Fish Biology. Proceedings of the Second International Conference on Indo-Pacific Fishes (eds Uyeano, T. et al.) (Ichthyological Society of Japan, Tokyo, 1986).

26. Sasaki, K. Comparative anatomy and phylogenetic relationships of the family Sciaenidae (Teleostei, Perciformes) (MS Hokkaido University, Sapporo, 1985).

27. Montie, E. W., Kehrer, C., Yost, J. \& Brenkert, K. Long-term monitoring of captive red drum Sciaenops ocellatus reveals that calling incidence and structure correlate with egg deposition. J. Fish Biol. 88, 1776-1795 (2016).

28. Locascio, J. V. \& Mann, D. A. Diel periodicity of fish sound production in Charlotte Harbor, Florida. Trans. Am. Fish. Soc. 137, 606-615 (2008).

29. Monczak, A., Berry, A., Kehrer, C. \& Montie, E. W. Long-term acoustic monitoring of fish calling provides baseline estimates of reproductive timelines in the May River estuary, southeastern USA. Mar. Ecol. Prog. Ser. 581, 1-19 (2017).

30. Lagardere, J. P. \& Mariani, A. Spawning sounds in meagre Argyrosomus regius recorded in the Gironde estuary, France. J. Fish Biol. 69, 1697-1708 (2006).

31. Skoglund, C. R. Functional analysis of swimbladder muscles engaged in sound productivity of the toadfish. J. Biophys. Biochem. Cytol. 10(Suppl), 187-200 (1961).

32. Fine, M. L., Malloy, K. L., King, C. B., Mitchell, S. L. \& Cameron, T. M. Movement and sound generation by the toadfish swimbladder. J. Comp. Physiol. 187A, 371-379 (2001).

33. Fine, M. L. \& Lenhardt, M. L. Shallow-water propagation of the toadfish mating call. Comp. Biochem. Physiol. 76A, 225-231 (1983).

34. Thorson, R. F. \& Fine, M. L. Crepuscular changes in emission rate and parameters of the boatwhistle advertisement call of the gulf toadfish, Opsanus beta. Environ. Biol. Fish. 63, 321-331 (2002).

35. Urick, R. J. Principles of Underwater Sound (McGraw-Hill, New York, 1975).

36. Lugli, M. \& Fine, M. L. Acoustic communication in two freshwater gobies: ambient noise and short-range propagation in shallow streams. J. Acoust. Soc. Am. 114, 512-521 (2003).

37. Mann, D. A. Propagation of fish sounds. In Communication in Fishes Vol. 1 (eds Ladich, F. et al.) 107-120 (Science Publishers, Enfield, 2006).

38. Ghahramani, Z. N., Mohajer, Y. J. \& Fine, M. L. Developmental variation in sound production in water and air in the blue catfish Ictalurus furcatus. J. Exp. Biol. 217, 4244-4251 (2014).

39. Akamatsu, T., Okumura, T., Novarini, N. \& Yan, H. Y. Empirical refinements applicable to the recording of fish sounds in small tanks. J. Acoust. Soc. Am. 112, 3073-3082 (2002).

40. Smith, M. E., Weller, K. K., Kynard, B., Sato, Y. \& Godinho, A. L. Mating calls of three prochilodontid fish species from Brazil. Environ. Biol. Fish 101, 327-339 (2018).

41. Minnaert, F. On musical air bubbles and the sounds of running water. Philos. Mag. 16, 235-248 (1933).

42. Weston, D. E. Sound propagation in the presence of bladder fish. In Underwater Acoustics Vol. 2 (ed. Albers, V. M.) 55-88 (Plenum Press, New York, 1967).

43. Batzler, W. E. \& Pickwell, G. V. Resonant acoustic scattering from gas-bladder fishes. In Proceedings of an International Symposium on Biological Sound Scattering in the Ocean (ed. Farquhar, G. B.) 168-179 (U.S. Government Printing Office, Washington, 1970).

44. McCartney, B. S. \& Stubbs, A. R. Measurement of the target strength of fish in dorsal aspect, including swimbladder resonance. In Proceedings of an International Symposium on Biological Sound Scattering in the Ocean (ed. Farquhar, G. B.) 180-211 (U.S. Government Printing Office, Washington, 1970).

45. Fine, M. L. Seasonal and geographic variation of the mating call of the oyster toadfish Opsanus tau. Oecologia 36, 45-57 (1978).

46. Fine, M. L., King, T. L., Ali, H., Sidker, N. \& Cameron, T. M. Wall structure and material properties cause viscous damping of swimbladder sounds in the oyster toadfish Opsanus tau. Proc. R. Soc. Lond. B 283, 1-9 (2016).

47. Parmentier, E., Lagardère, J. P., Braquegnier, J. B., Vandewalle, P. \& Fine, M. L. Sound production mechanism in carapid fish: first example with a slow sonic muscle. J. Exp. Biol. 209, 2952-2960 (2006).

48. Parmentier, E., Fine, M. L. \& Mok, H. K. Sound production by a recoiling system in the Pempheridae and Terapontidae. J. Morphol. 277, 717-724 (2016).

49. Parmentier, E. \& Fine, M. L. Fish sound production: insights. In Vertebrate Sound Production and Acoustic Communication (eds Suthers, R. A. \& Fitch, T.) 19-49 (Springer, New York, 2016).

50. Ramcharitar, J. U., Deng, X., Ketten, D. \& Popper, A. N. Form and function in the unique inner ear of a teleost: the silver perch (Bairdiella chrysoura). J. Comp. Neurol. 475, 531-539 (2004).

51. Robertson, G. N., McGee, C. A. S., Dunbarton, T. C., Croll, R. P. \& Smith, F. M. Development of the swimbladder and Its innervation in the zebrafish, Danio rerio. J. Morphol. 268, 967-985 (2007).

52. Birindelli, J. L. O., Sousa, L. M. \& Sabaj Perez, M. H. Morphology of the gas bladder in thorny catfishes (Siluriformes: Doradidae). Proc. Acad. Nat. Sci. Philadelphia 158, 261-296 (2009).

53. Borie, A. et al. Disturbance calls of five migratory Characiformes species and advertisement choruses in Amazon spawning sites. J. Fish Biol. 95, 820-832 (2019).

54. King, T. L. The Relationship Between Collagen Fibers and Material Properties of Swim Bladders in Sonic Teleosts. MS Virginia Commonwealth University (2005).

55. Connaughton, M. A., Fine, M. L. \& Taylor, M. H. Weakfish sonic muscle: influence of size, temperature and season. J. Exp. Biol. 205, 2183-2188 (2002).

56. Locascio, J. V. \& Mann, D. A. Localization and source level estimates of black drum (Pogonias chromis) calls. J. Acoust. Soc. Am. 130, 1868-1879 (2011).

57. Bradbury, J. W. \& Vehrencamp, S. L. Principles of Animal Communication (Sinauer, Massachusetts, 1998).

58. Ramcharitar, J. U., Higgs, D. M. \& Popper, A. N. Audition in sciaenid fishes with different swim bladder-inner ear configurations. J. Acoust. Soc. Am. 119, 439-443 (2006).

59. Salas, A. K., Wilson, P. S. \& Fuiman, L. A. Ontogenetic change in predicted acoustic pressure sensitivity in larval red drum (Sciaenops ocellatus). J. Exp. Biol. 222, 1-12 (2019).

60. Rice, A. N., Soldevilla, M. S. \& Quinlan, J. A. Nocturnal patterns in fish chorusing off the coasts of Georgia and eastern Florida. Bull. Mar. Sci. 93, 455-474 (2017).

61. Sprague, M. W. The single sonic muscle twitch model for the sound-production mechanism in the weakfish, Cynoscion regalis. J. Acoust. Soc. Am. 108, 2430-2437 (2000).

62. Picculin, M. et al. Diagnostics of nocturnal calls of Sciaenaumbra (L., fam. Sciaenidae) in a nearshore Mediterranean marine reserve. Bioacoustics 12, 292-294 (2012).

63. Tellechea, J. S. \& Norbis, W. Sexual dimorphism in sound production and call characteristics in the striped weakfish Cynoscion guatucupa. Zool. Stud. 51, 946-955 (2012).

64. Rountree, R. A. \& Juanes, F. Potential of passive acoustic recording for monitoring invasive species: freshwater drum invasion of the Hudson River via the New York canal system. Biol. Invasions 19, 2075-2088 (2017).

65. Tellechea, J. S., Fine, M. L. \& Norbis, W. Passive acoustic monitoring, development of disturbance calls and differentiation of disturbance and advertisement calls in the Argentine croaker Umbrina canosai (Sciaenidae). J. Fish Biol. 90, 1631-1643 (2017).

66. Tang, S. K. On Helmholtz resonators with tapered necks. J. Acoust. Soc. Am. 279, 1085-1096 (2005).

67. Pillaia, M. A. \& Da, E. Improved acoustic energy harvester using tapered neck Helmholtz resonator and piezoelectric cantilever undergoing concurrent bending and twisting. Procedia Eng. 144, 674-681 (2016). 
68. Yoshida, T. et al. (eds) Fishes of Northern Gulf of Thailand (National Museum of Nature and Science, Tuskuba, 2013).

\section{Acknowledgements}

We thank R. Sematong for allowing us to record fish sounds at the hatchery, S. Shiue and P.H. Chiu for logistical assistance, S.H. Liu for photography, and B. Lipkins and T. Cameron for advice on Helmholz absorption. This study was funded by a grant to HKM from the Ministry of Science and Technology (MOST) of the Republic of China. Field trip to Thailand was also partly supported by a MOST grant awarded to K. Soong, Department of Oceanography, National Sun Yat-sen University.

\section{Author contributions}

H.K.M. initiated the study, H.K.M., S.C.W. and S.S. recorded calls, S.S. collected specimens for anatomical examination, H.K.M and S.C.W. and M.L.F. analyzed data, M.L.F. and H.K.M wrote the paper. All authors approved the submission.

\section{Competing interests}

The authors declare no competing interests.

\section{Additional information}

Correspondence and requests for materials should be addressed to M.L.F.

Reprints and permissions information is available at www.nature.com/reprints.

Publisher's note Springer Nature remains neutral with regard to jurisdictional claims in published maps and institutional affiliations.

(c) (i) Open Access This article is licensed under a Creative Commons Attribution 4.0 International

License, which permits use, sharing, adaptation, distribution and reproduction in any medium or format, as long as you give appropriate credit to the original author(s) and the source, provide a link to the Creative Commons licence, and indicate if changes were made. The images or other third party material in this article are included in the article's Creative Commons licence, unless indicated otherwise in a credit line to the material. If material is not included in the article's Creative Commons licence and your intended use is not permitted by statutory regulation or exceeds the permitted use, you will need to obtain permission directly from the copyright holder. To view a copy of this licence, visit http://creativecommons.org/licenses/by/4.0/.

(C) The Author(s) 2020 